\title{
Communication
}

\section{Coptic Language Learning and Social Media}

\section{Nicole Deschene}

Department of Teaching and Learning, New York University, New York, NY 10003, USA; nicole.deschene@nyu.edu

Received: 1 August 2019; Accepted: 9 September 2019; Published: 11 September 2019

check for updates

\begin{abstract}
This study explored the potential of using the Internet, including existing social media platforms, for Coptic language learning. Through global exposure, endangered language maintenance and revitalization efforts may benefit from having a presence on social media. The researcher created Coptic language learning material, social media accounts on multiple platforms, and a website. Data were collected through a survey with questions focused on social media users' background and experience with the Coptic language learning material. In addition to the survey, analytics from the social media and website platforms were documented. The results indicated that social media provided a global audience and the Coptic language learning material blended into survey respondents' daily lives with positive acceptance.
\end{abstract}

Keywords: Coptic; social media; language learning; endangered language; language revitalization; language maintenance

\section{Introduction}

The rapid development of mobile technology continually creates new opportunities for language learning. These new opportunities include novel approaches to language education as well as platforms for exposure to endangered languages (Cunliffe 2007). There are 7111 languages in the world (Eberhard et al. 2019) and the majority of languages are endangered (Krauss 2007). Languages can be classified as extinct if speakers no longer exist or, on the other end of the spectrum, safe if the number of speakers is expected to grow. In between extinction and safety, there are several degrees of endangerment (Krauss 2007). Coptic, a language of Egyptian origin, associated with the Coptic Orthodox Church (Takla 2014), is among the languages that are classified as severely endangered, dormant, or even extinct (Eberhard et al. 2019). What can be done to support and protect such endangered languages and prevent their loss? Crystal (Crystal 2014) theorized factors that can strengthen the position of endangered languages; among them is the use of electronic technology. The study presented here explores how the affordances of technology can be engaged as a resource to restore and develop the Coptic language.

\section{Background}

Motivated individuals and communities have served as actors for language revitalization and maintenance efforts. They employ various strategies to strengthen the position of an endangered language, such as the establishment of immersion schools. This approach has been examined for the Hawaiian (Warner 2001), Ojibwe, and Māori languages (Hermes and Kawai'ae'a 2014), among others. Although the literature largely focuses on revitalization efforts that are still in progress, research has reviewed past success of similar efforts. For example, an exemplary case of language revitalization is that of Hebrew. Over the course of approximately 25 years, starting at the end of the nineteenth century, the position of Hebrew strengthened dramatically through a persistent effort. This success 
can partly be attributed to the consistent and centuries-long use of Hebrew as a religious language for Jewish prayer (Spolsky 1995).

Recently, ongoing language revitalization efforts have been incorporating electronic technology as a tool for language learning outside of traditional education settings. The language learning application Duolingo currently offers 33 language courses for English speakers, including several endangered languages. In addition to the 21.8 million learners of Spanish, Duolingo also claims to have 173 thousand learners of Navajo, 286 thousand learners of Hawaiian, and 336 thousand learners of Welsh (Duolingo n.d.). Still, mainstream language learning technology such as Duolingo has not accommodated the needs of all endangered language learners. Efforts, such as that of Ojibwe, have found it necessary to create their own language learning material. Hermes and King (2013) examined the use of a computer software program among families of beginner level Ojibwe language learners. The software included videos, flash cards, games, exercises, and quizzes. The participants consistently used the software over a period of eight weeks by dedicating time to use it each day. The results from the study suggested that the consistent use of the software provided the adult participants in particular with the confidence and skills that they needed to start using the language.

More specifically within electronic technology, research suggests that the Internet has been used for endangered language learning through various websites and applications. Although there are people without access to the Internet, the Internet provides equality for communities that may not be able to afford traditional sources of media (Crystal 2014) and do have access to the Internet. For example, Jones (2015) investigated the use of digital technology for Welsh language learning. All of the participants in Jones' study reported using the Internet in various ways to learn Welsh. They watched YouTube videos, read Facebook and blog posts, wrote emails, participated in Skype conversations, created iTunes U flash cards, and used Google Translate. They also used language learning resources and viewed Welsh television programs on British broadcast websites.

\subsection{Social Media}

Social media is potentially effective because it is ubiquitous and manageable. It incorporates feeds that provide mobile device users with small segments of information. Common practice of mobile social media involves moving through a feed while absorbing information actively or passively. The Pew Research Center reported that within the United States, 74\% of Facebook users, $63 \%$ of Snapchat users, $60 \%$ of Instagram users, $46 \%$ of Twitter users, and $45 \%$ of YouTube users access the platforms at least once a day (Smith and Anderson 2018). Jones et al. (2013) investigated the use of Twitter among Welsh speakers. The results indicated that the majority of participants expected to read and write in Welsh when they signed up for a Twitter account and chose to follow other Twitter accounts based on their use of Welsh. They considered Twitter to be an easy platform to frequently produce and engage with Welsh content as well as connect with other Welsh speakers.

Thus, through global exposure, endangered language maintenance and revitalization efforts can benefit from having a presence on social media. Stern (2017) explored the role of Facebook in Balinese revitalization efforts by administrators and members of a Facebook group. Although the group page was visible to the public, only members of the group could post. The members of the group, mostly teenagers and young adults, posted a variety of content in Balinese, but not necessarily about the Balinese language. The results suggested that the presence of Balinese on Facebook transcended time and space by reaching an international audience that could interact continuously. Similarly, Cru (2015) explored the role of Facebook in Yucatec Maya revitalization efforts. The results indicated that youth encouraged the use of Yucatec Maya by posting in the language. Other Facebook users engaged with the posts by reading and replying to them, creating a written dialogue. Although most of the post replies indicated that users had some degree of proficiency in the language, one example indicated that a Facebook user was not proficient enough in the language to use it but was interested in learning it. The results suggested that the presence of Yucatec Maya on Facebook could reach speakers and learners on a global level and appeal to youth because of the relevance of Facebook in their modern lives. 


\subsection{Coptic Language}

The present study explored the presence of social media specifically dedicated to Coptic language learning. Coptic is an indigenous language of Egypt and a member of the Afroasiatic language family. It is the last stage of the Ancient Egyptian language, which dates back to $3000 \mathrm{BC}$. The writing systems of the Egyptian language evolved from the hieroglyphic system to Hieratic, and then Demotic (Loprieno and Müller 2012). By the third century BC, the Egyptian writing system further evolved to incorporate Greek, a dominant language at the time, and was henceforth referred to as Coptic.

Coptic was once the majority language in Egypt with different regional dialects, but it slowly became a minority language (Ishaq 1991). Although empirical research on the vitality of the Coptic language has yet to be conducted, organizations still estimate the vitality of the language. For example, UNESCO currently classifies the Coptic language as extinct (Moseley 2010) based on their language vitality and endangerment framework. Extinct is the highest degree of endangerment within this framework and implies that there are no speakers left (Brenzinger et al. 2003). Another organization, SIL International, recently updated their classification of Coptic based on a different framework, the Expanded Graded Intergenerational Disruption Scale. Coptic was previously classified as dormant, which is the last level of endangerment before extinct. A dormant language is defined as only being used symbolically for ethnic identity (Simons and Fennig 2018). The current classification of Coptic was downgraded to second language only, which is defined as no longer being a heritage language of an ethnic community (Eberhard et al. 2019). This updated classification may not accurately depict the vitality of the language, including one of its dialects, Bohairic.

Despite Coptic language loss, the Coptic dialect, Bohairic, has been used continuously within the Coptic Orthodox Church. Bohairic Coptic has survived for centuries in a diglossic context (Ishaq 1991) along with Arabic. Priests, deacons, and parishioners continue to perform Coptic hymns during church services. These hymns have been performed throughout the history of the Coptic Orthodox Church (Ramzy 2013). Although priests and deacons can use other languages in religious services, they often choose to use Coptic in order to maintain the rhythmic and melodic musical features that incorporate the syllabic features of the Coptic language (Ragheb 2018). Furthermore, Coptic language education has continued through classes organized by churches and through books published by churches (Younan 2005).

In the 1960s, the Coptic diaspora started growing in North America, Europe, and Australia (Botros 2006). Through migration, the use of the Coptic language expanded beyond the borders of Egypt. Churches in the diaspora mount screens that display the text of the liturgy in real time in three languages side-by-side, Arabic, Coptic, and English (Saad 2010). Forms of electronic media, such as satellite television broadcasting, Internet streaming, mobile applications, and social network platforms, have connected Copts throughout the diaspora as well as Copts in Egypt. Electronic media has created a Coptic community that is not separated or divided by territorial borderlines (Westbrook and Saad 2017). Although the literature highlights the use of electronic media within the Coptic community, questions still remain about the use of electronic media for Coptic language learning.

\subsection{Research Questions}

The researcher developed digital resources for learners of Coptic and made them available to the public via the Internet. The research questions that this study addresses are:

1. Who would use Coptic language learning material made available on the Internet?

2. How would they describe their experience using the Coptic language learning material?

3. How much exposure would the Coptic language learning material receive?

\section{Materials and Methods}

The researcher created Coptic language learning material, social media accounts on multiple platforms, and a website. The social media accounts were public and were created on Facebook, 
Instagram, and Twitter. The posts on the social media accounts were consistent with each other and anyone could view posts, regardless of whether they had an account or not, and regardless of whether or not they were followers of the account. The website was created using WordPress and included all of the content posted on the social media accounts as well as additional resources. Links to the website were included on the social media accounts.

The language learning materials that were posted first consisted of short videos for each Coptic phoneme-grapheme correspondence. There are 31 letters and 1 number in the Coptic alphabet. The majority of the letters in the Coptic alphabet are Greek letters. However, 7 of the letters are Demotic, which is the previous writing system for the spoken Coptic language (Ishaq 1991). Phoneme-grapheme correspondence was chosen as the focus of the initial language learning materials because decoding is a necessary skill in reading (Gough and Tunmer 1986). A video was created for each letter with a format that consisted of an image of the lowercase letter with a voice recording of the letter name and letter sound, followed by the uppercase letter with a repeat of the voice recording of the letter name and letter sound (see Figure 1). Research has shown that learning letter names is beneficial for learning letter sounds and reading (Foulin 2005). Videos were also created for letter combinations that corresponded with different sounds.

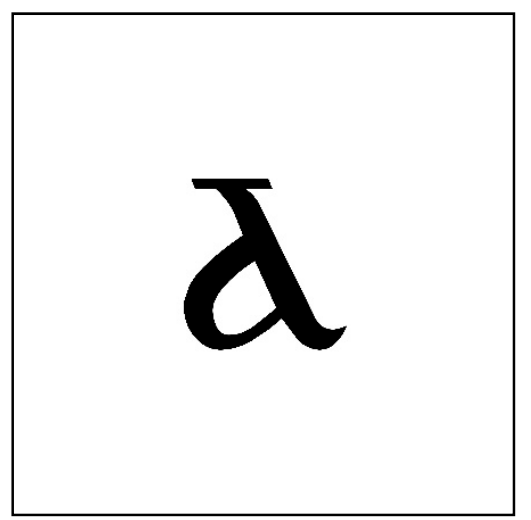

(a)

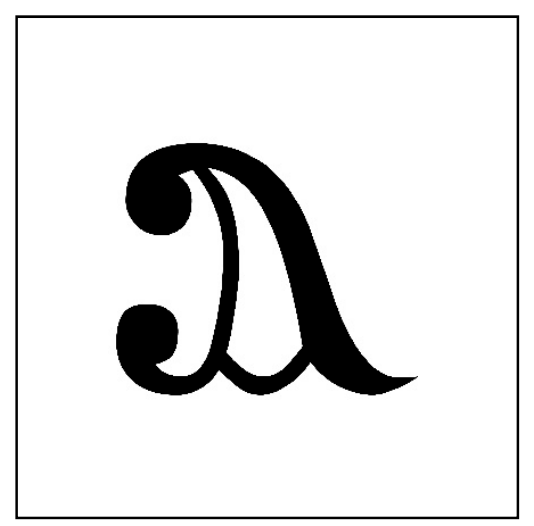

(b)

Figure 1. Video frames of the first letter of the Coptic alphabet. (a) Lowercase; (b) Uppercase.

In 2018, the first 38 videos were posted one at a time, every day, and were organically promoted mostly through the use of hashtags (i.e., \#coptic). Hashtags allow social media users to share and discover content based on phrases or words that describe the content. A short description accompanied each video post. Although the descriptions were in English, they could be translated into other languages using the platforms' translation tools. The description for the first video was This is the name and sound of the first letter of the Coptic alphabet.

A survey was developed, and then created on Qualtrics, to collect information from social media users. Usability tests and retrospective think-alouds were conducted in order to pretest the survey (Groves et al. 2009). The survey had a total of 27 questions, including sub questions, focused on social media users' background and experience with the Coptic language learning material. The items included multiple choice, Likert scale, and short open-ended responses (see Appendix A). The survey was anonymous and conducted in English. Immediately after the first 38 videos were posted, requests to participate in the anonymous survey were posted. The survey was only active for one week. The timing of the survey was designed to increase the accuracy of the respondents' memory recall on questions such as, How often did the videos appear in your social media feed? All respondents provided their informed consent before completing the survey. All of the open-ended responses were manually coded by the researcher and then organized into themes that emerged from the data (Saldaña 2016).

In addition to the survey, web analytics from the social media accounts and the website were documented. This included the number of video views on each of the social media accounts, the 
number of visitors and the number of page views on the website, as well as the country location of the visitors on the website. This study, IRB-FY2018-2096, was approved by the author's University Committee on Activities Involving Human Subjects.

\section{Results}

\subsection{Survey}

During the one-week time frame that the survey was active, 27 respondents submitted the survey. However, one respondent's survey was deleted because it was incomplete, leaving a total of 26 respondents. Based on the small sample size, descriptive statistics were used to report on the quantitative data collected from this group of social media users.

\subsubsection{Respondent Demographics}

The results from the background questions indicated that the respondents' average age was 28.5 years (S.D. = 9). They lived in the United States, Australia, Canada, and Italy. They were born in the United States, Egypt, Australia, Canada, Italy, and Germany.

\subsubsection{Respondent Language Background}

The respondents reported having some degree of proficiency in languages including English, Arabic, Spanish, French, German, and Italian, which all have different writing systems than Coptic. Additionally, 12 of the respondents reported having some degree of proficiency in Coptic and ranked their proficiency in speaking, listening, reading, and writing on a scale of 0 to 5 , with 5 being described as fluent. Their average self-reported proficiency in speaking was 1.67 (S.D. = 1.03), listening was 1.92 $($ S.D. $=1.08)$, reading was 2.25 (S.D. $=1.36)$, and writing was 0.75 (S.D. $=0.75)$.

Only 10 of the respondents had taken a Coptic language class in the past and they all reported that their Coptic language class was held at a church. Exactly half of the respondents reported that they had tried to teach themselves Coptic. As illustrated by the sampling of responses in Table 1, some described their challenging experience teaching themselves Coptic, whereas others described the strategies that they used to teach themselves the language.

Table 1. Description of experience teaching oneself the Coptic language.

\begin{tabular}{|c|c|}
\hline Theme & Responses \\
\hline $\begin{array}{l}\text { Challenging } \\
\text { experience of } \\
\text { teaching oneself }\end{array}$ & $\begin{array}{l}\text { "Impossible! Books are too verbose and an impersonal way to learn a language so far from } \\
\text { English/Arabic in structure" } \\
\text { "I have only just started but the differences between Bohairic and Sahidic are annoying to } \\
\text { decipher and there are not many resources dedicated to Coptic as a social language, } \\
\text { more liturgical" } \\
\text { "Difficult" } \\
\text { "Frustrating to learn by yourself" }\end{array}$ \\
\hline $\begin{array}{l}\text { Strategies used } \\
\text { to teach oneself }\end{array}$ & $\begin{array}{l}\text { "I learnt the alphabet in a week and then practiced reading every day for a few months. } \\
\text { Once a week I would ask one of the boys from church to let me read to them so they could } \\
\text { fix my mistakes and help with pronunciation" } \\
\text { "Just learning vocabulary by comparing translations during liturgy or other services" } \\
\text { "I occasionally study it with a friend, brush up with a book, or occasionally attend a Coptic } \\
\text { Orthodox Church but not regularly" } \\
\text { "Learning Greek alphabet and reading Coptic icons" } \\
\text { "My husband helped me learn to read it" } \\
\text { "Mainly learning through reading the translation in the liturgy book" }\end{array}$ \\
\hline
\end{tabular}

When asked why they were interested in learning the Coptic language, their reasons, which are listed in Table 2, included comprehension of and participation in worship, the ability to read 
ancient manuscripts, preservation of the Coptic heritage and language, as well as the historical value of the language.

Table 2. Source of interest for learning the Coptic language.

\begin{tabular}{ll}
\hline \multicolumn{1}{c}{ Theme } & \multicolumn{1}{c}{ Responses } \\
\hline $\begin{array}{l}\text { Comprehension of } \\
\text { and participation } \\
\text { in worship }\end{array}$ & $\begin{array}{l}\text { "I am interested in learning the Coptic language because it is the language of our } \\
\text { fathers and so I may participate in the hymns of the church" } \\
\text { "Understanding the liturgy more and being able to teach my child" } \\
\text { "Understand church services better" }\end{array}$ \\
\hline $\begin{array}{l}\text { "At first it was to be able to sing Coptic hymns, now I think I would take it further to be } \\
\text { ancient manuscripts to read manuscripts" }\end{array}$ & $\begin{array}{l}\text { "For worship, and to explore further the ancient manuscripts and stories of desert } \\
\text { fathers and mothers" }\end{array}$ \\
\hline $\begin{array}{l}\text { "I am interested in ancient Coptic manuscripts and writings" } \\
\text { "Treservation of the } \\
\text { heritage and } \\
\text { language }\end{array}$ & $\begin{array}{l}\text { "Heritage. While I believe that prayer should be easy to understand for all, I also don't } \\
\text { "Lant our Coptic heritage to die" }\end{array}$ \\
\hline $\begin{array}{l}\text { "Tanguage revival of my ancestors" } \\
\text { "To preserve the language of our forefathers" }\end{array}$ \\
$\begin{array}{l}\text { "The heritage of the Coptic people needs preservation" } \\
\text { the language }\end{array}$ \\
\hline
\end{tabular}

\subsubsection{Respondent Experience with the Coptic Language Learning Material}

The results from the questions that focused on their experience with the Coptic language learning material indicated that many of the respondents used more than one type of device and more than one type of platform to view the videos. Twenty-five of the respondents used a smartphone to view the videos, 9 used a laptop, 3 used a tablet, and 3 used a desktop. Eighteen viewed the videos on Instagram, 8 viewed the videos on Facebook, 4 viewed the videos on Twitter, and 3 viewed the videos on the website. As shown in Figure 2, twelve reported that the videos appeared in their social media feed once a day, 11 reported that they appeared once every few days, 2 reported that that they appeared more than once a day, and only 1 reported that they never appeared in their social media feed. Fifteen viewed the videos 1 time and 11 viewed the videos $2-5$ times. Eight reported that they always had sound on while viewing the videos, 11 had sound on most of the time, 2 had sound on about half the time, and 5 had sound on sometimes.

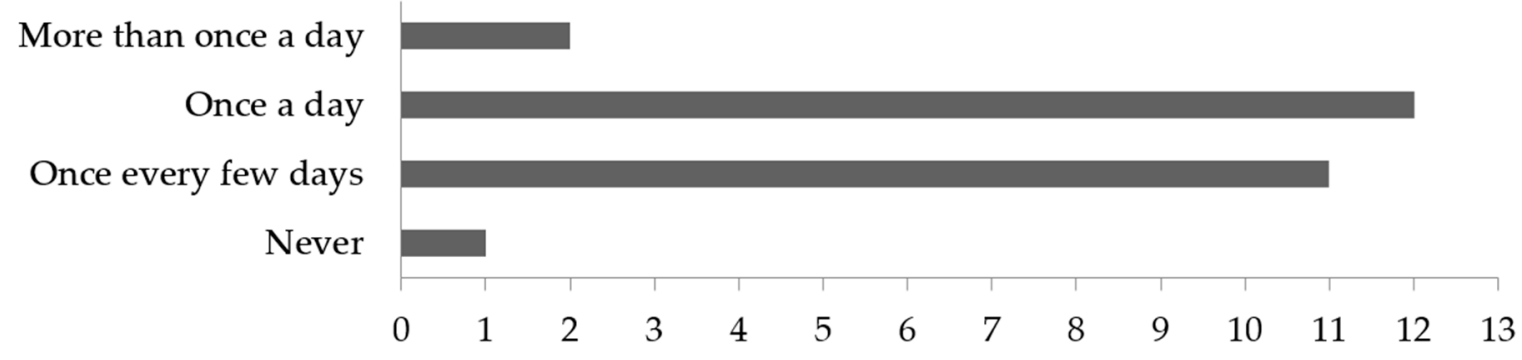

Figure 2. Frequency of video appearance on social media feed.

Exactly half of the respondents reported that the content helped them learn letter names, 16 reported that it helped them learn letter sounds, 9 reported that it helped them learn letter combination sounds, and 5 reported that it helped them find other Coptic language learning resources. Twenty-four reported that they were interested in continuing to learn Coptic, whereas only 2 reported that they 
were unsure if they would continue to learn Coptic, and none of the respondents reported that they were not interested in continuing to learn.

In response to an open ended question that asked the respondents to provide additional information about their experience, they reported that, "It was great, I've never had a resource for learning another language on social media"; "Very useful to understand the language and know how it sounds"; "Videos are straightforward and reliably the same high quality"; It is not my first exposure to the Coptic language so I mostly viewed it to make sure that what I had previously learned was the same as what was on this site"; "Personally need more usage examples and context to learn".

\subsection{Web Analytics}

After the social media accounts and the website were launched, web analytics were documented. At the time of the survey administration, the website had a total of 50 visitors and 125 page views. The country locations of the website visitors included the United States, Canada, the United Kingdom, Egypt, Australia, and Russia. One year later, the website had accumulated a total of 249 visitors and 847 page views. The website pages that contain the phoneme-grapheme correspondence videos accumulated a total of 107 views. The country locations of the website visitors included the addition of Germany, France, China, Mexico, Italy, Indonesia, Ireland, Japan, Mongolia, Seychelles, the United Arab Emirates, and Sweden. Figure 3 shows a world map of the country locations of the website visitors. Visitors clicked on the website link 124 times through the Facebook, Instagram, and Twitter accounts, as well as 34 times through search engine results from Google, Yahoo, and Bing.

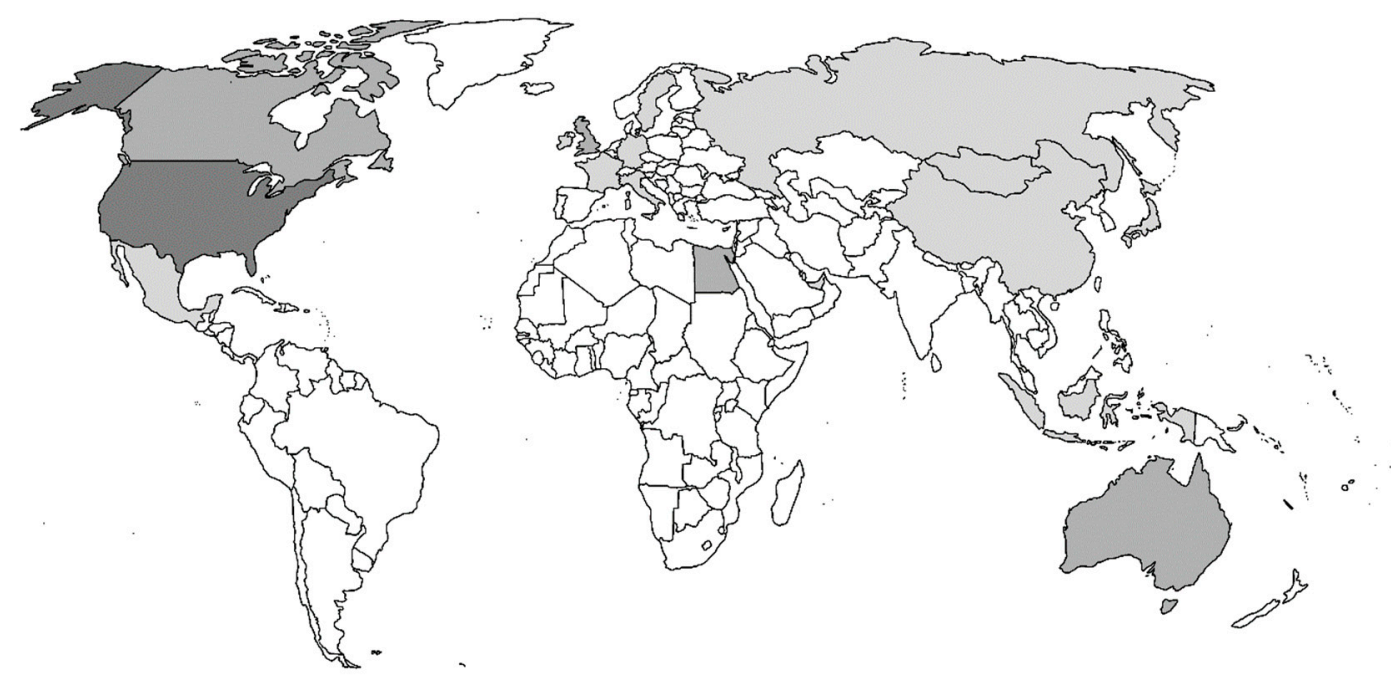

Figure 3. World map of website visitor country locations.

The number of views for each of the first 38 videos posted on Facebook, Instagram, and Twitter were added together as the total number of views per video. The video views were added together for this initial stage of the research, as the comparison of the different social media platforms would be premature at this stage. One year after the 38th video was posted, the combined total number of video views was 3049. The average number of views per video was 80.24 (S.D. $=38.52$ ) and the range of the total number of views per video was 31 to 241 . Figure 4 shows a quadratic regression model of the total number of views per video and the order that the videos were posted. The video that was viewed the most was the first video that was posted and the video that was viewed the least was the sixteenth video that was posted. 


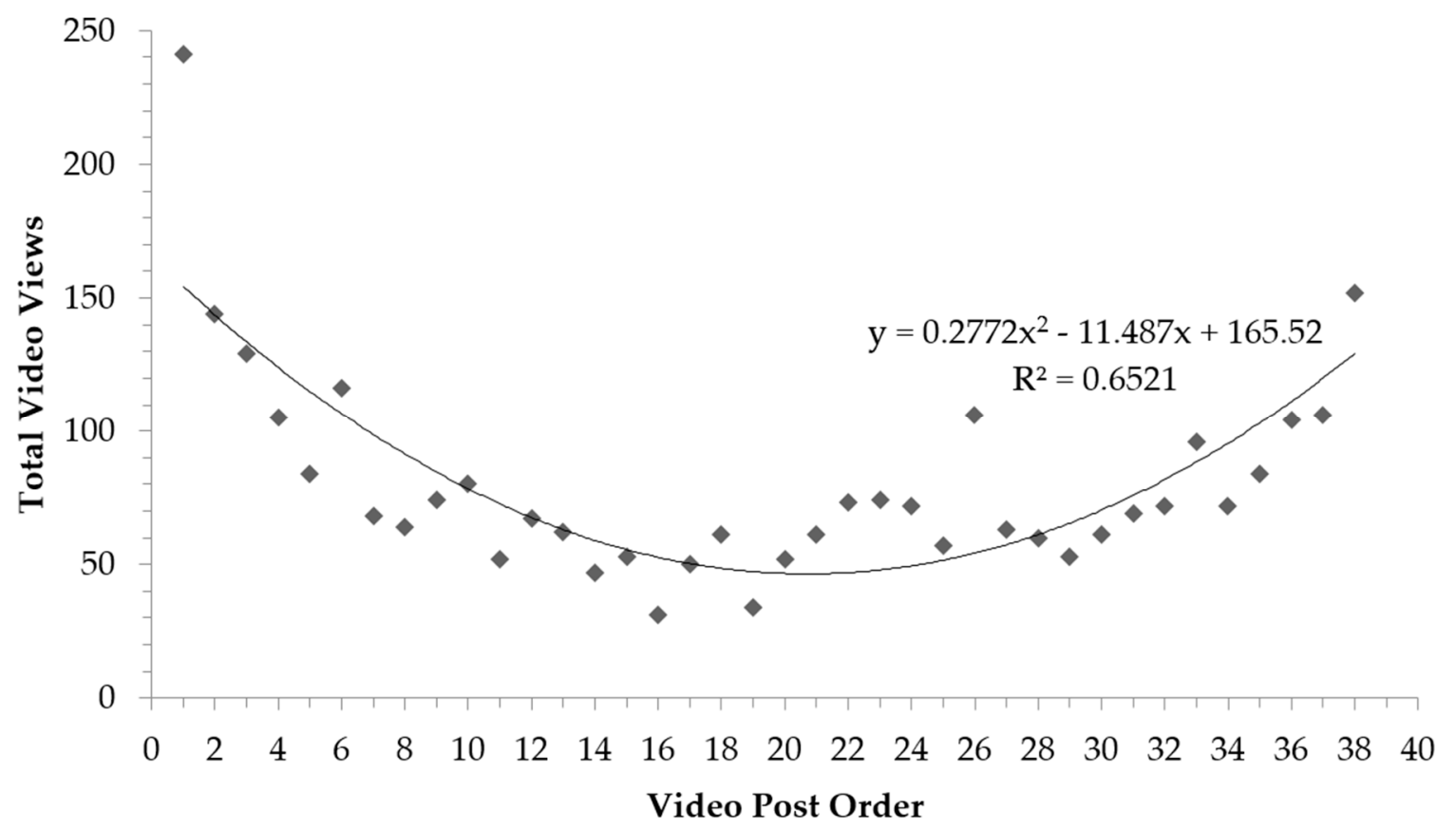

Figure 4. Quadratic regression model of total video views and video post order.

\section{Discussion}

\subsection{Research Question 1}

The results from the survey background questions, as well as the website analytics, address the first research question by describing the people who used Coptic language learning material made available on the Internet. Overall, the survey respondents and the website visitors were an international group that were located in the United States, Canada, the United Kingdom, Egypt, Australia, Russia, Germany, France, China, Mexico, Italy, Indonesia, Ireland, Japan, Mongolia, Seychelles, the United Arab Emirates, and Sweden. This finding aligns with the literature that describes the Coptic diaspora having started in North America, Europe, and Australia (Botros 2006). This finding also supports suggestions in the literature that the Internet provides endangered language revitalization and maintenance efforts with a global audience (Cru 2015; Stern 2017). Considering the overall low cost of this effort, and that the content was mostly promoted organically through the use of hashtags within a short period of time, the results suggest that the Coptic language learning material developed a presence on the Internet. However, it may be beneficial for future efforts to promote websites and social media accounts more actively if the goal is to create a wider presence.

All of the survey respondents that indicated that they had taken a Coptic language class in the past reported that the classes were held at a church. This supports the notion that Coptic language education has continued through classes organized by churches (Younan 2005). Almost half of the survey respondents reported that they had some degree of proficiency in Coptic. However, their average self-reported proficiency levels in speaking, listening, reading, and writing were low. This may suggest that language learning material on social media may be especially useful for beginners. This could also suggest that posting beginner level language learning material on social media may attract beginner learners. Half of the respondents reported that they had tried to teach themselves the Coptic language and explained the challenges they experienced as well as the techniques they used. Although it is common for people to teach themselves a language, the results suggest that Coptic language learners may not have the variety of self-teaching resources that other language learners have (Duolingo n.d.).

Several of the survey respondents attributed their interest in learning the Coptic language to reasons related to the preservation of their Coptic heritage. This contradicts the current classification of Coptic in the literature. SIL International classifies Coptic as second language only, which is defined 
as no longer being a heritage language of an ethnic community (Eberhard et al. 2019). Further research could determine the vitality of the Coptic language and could update classifications if necessary.

\subsection{Research Question 2}

Results from the survey address the second research question by describing people's experience using the Coptic language learning material made available on the Internet. The Coptic language learning material blended into the respondents' daily lives with positive acceptance. More than half of them reported that posts appeared in their social media news feed at least once a day. This suggests that the language learning material was often delivered to the learner without requiring the learner to actively seek it. As reviewed in the literature, the development of confidence and skills in the language learning process benefits from consistency (Hermes and King 2013), which further supports the important role that social media can have in learning any language.

Almost all of the respondents reported that they used a smartphone to access the language learning material, which suggests that social media users may be mobile. The development of language learning material for social media should take mobility into consideration. One of the respondents commented on the high quality and straightforwardness of the videos. Although the language learning material was provided to the public informally and without financial cost, it was still designed purposefully and created carefully. Another respondent commented on the usefulness of knowing how the language sounds. Furthermore, all of the respondents indicated that they had the sound on while watching the videos at least sometimes and more than half indicated that they had the sound on at least most of the time. The availability of audio is particularly salient for learners of an endangered language because access to the spoken language may be limited.

\subsection{Research Question 3}

Results from the web analytics address the third research question by quantifying the exposure of the Coptic language learning material based on social media video views, website page views, and website visitors. Over the timespan of one year, the videos posted on social media accumulated a total of over three thousand views and more than two hundred people visited the website. This supports the theory that electronic technology, including the Internet, has the potential to help strengthen the position of endangered languages (Crystal 2014).

A possible explanation for the range between the video with the most views and the video with the least views could be the order that they were posted. Social media users that discovered the social media accounts may have viewed the most recent posts and may also have been interested in viewing the earliest posts. However, social media users that were actually using the language learning material may have viewed all of the posts, including those in the middle. The content of the videos was limited to phoneme-grapheme correspondences, which may not have been useful for every social media user that discovered the accounts. Although decoding is a necessary skill in reading (Gough and Tunmer 1986), it is a beginner level skill that more proficient language learners may already have.

It should be expected that social media users have different needs based on their varying levels of proficiency. This is similar to what was reviewed in the literature. The majority of the members of a Yucatec Maya Facebook page were proficient enough to communicate with each other. However, one member was interested but was not proficient enough to join the conversation (Cru 2015). Future efforts should determine what content would be most useful but not be discouraged by low engagement. Older content can be reposted if it is determined that it needs more exposure. Furthermore, future research could examine the relationship between social media post engagement and post order over a longer period of time and with a variety of content.

\section{Conclusions}

This study must be considered purely exploratory. The sample was self-selected and may not be representative of the larger population with an interest in learning Coptic. Moreover, promotion was 
limited and time for the project was constrained. Although generalizations cannot be made from the small self-selected sample size, the results are still promising and can guide future research related to the Coptic language, as well as other endangered languages.

Future research should focus on the vitality of the Coptic language. The current classification of the language did not align with the survey respondents' comments regarding its role as a heritage language. Therefore, it should be determined if the position of the language is different than what is depicted in the literature. Furthermore, the vitality of Coptic, as well as other endangered languages, should be measured on more than one occasion, and over time, to determine if revitalization and maintenance efforts are effective in improving the position of the language.

The use of existing platforms, such as social media, for language learning should continue to be examined. The majority of the survey respondents in this study reported that they learned from the posts and were interested in continuing to learn the Coptic language. Future research could focus on the effectiveness of learning an endangered language through social media through longitudinal studies.

In addition to providing direction for future research, the implications of global exposure should be promising for endangered language efforts. The survey respondents and the website visitors in this study were people with Internet access that were located all over the world. A global audience is essential for endangered language exposure since diasporas take their languages outside of their indigenous boundaries.

Funding: This research received no external funding.

Acknowledgments: The author thanks the survey respondents for their participation in this study, as well as Miriam Eisenstein Ebsworth for her feedback and guidance.

Conflicts of Interest: The author declares no conflict of interest.

\section{Appendix A Survey}

1. How old are you?

2. What country were you born in?

3. What country do you live in?

4. What languages do you know? Select all that apply.

$\square$ Arabic $\square$ Coptic $\square$ English $\square$ Other

4.1. Rate your Arabic proficiency. 4.1.a. Speaking 4.1.b. Listening 4.1.c. Reading 4.1.d. Writing $\square 0 \square 1 \square 2 \square 3 \square 4 \square 5$ Fluent

4.2. Rate your Coptic proficiency. 4.2.a. Speaking 4.2.b. Listening 4.2.c. Reading 4.2.d. Writing $\square 0 \square 1 \square 2 \square 3 \square 4 \square 5$ Fluent

4.3. Rate your English proficiency. 4.3.a. Speaking 4.3.b. Listening 4.3.c. Reading 4.3.d. Writing $\square 0 \square 1 \square 2 \square 3 \square 4 \square 5$ Fluent

5. What languages were used in your home when you were a young child? Select all that apply. $\square$ Arabic $\square$ Coptic $\square$ English $\square$ Other

6. Do you attend a Coptic Orthodox church?

$\square$ Yes $\square$ No

6.1. At what age did you start attending a Coptic Orthodox church?

$\square$ Under 3 years old $\square$ 3-11 years old $\square$ 12-18 years old $\square$ Over 18 years old 
6.2. What languages are used in the church services you attend? Select all that apply.

$\square$ Arabic $\square$ Coptic $\square$ English $\square$ Other

7. Have you ever taken a Coptic language class?

$\square$ Yes $\square$ No

7.1. Where have you taken Coptic language classes? Select all that apply.

$\square$ At a church $\square$ At a college or university Other

8. Have you ever tried to teach yourself the Coptic language?

$\square$ Yes $\square$ No

8.1. Describe your experience teaching yourself the Coptic language.

9. Why are you interested in learning the Coptic language?

10. What types of devices did you use to view videos from Coptic Literacy? Select all that apply.

$\square$ Smartphone $\square$ Tablet $\square$ Laptop $\square$ Desktop

11. Where did you view videos from Coptic Literacy? Select all that apply.

$\square$ Website $\square$ Facebook $\square$ Instagram $\square$ Twitter

12. How many Coptic Literacy videos have you viewed?

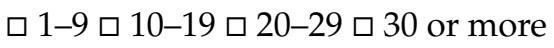

13. How many times do you typically view each Coptic Literacy video?

$\square 1$ time $\square 2-5$ times $\square$ More than 5 times

14. How often did videos from Coptic Literacy appear in your social media feed?

$\square$ Never $\square$ Once every few days $\square$ Once a day $\square$ More than once a day

15. How often did you have sound on while viewing videos from Coptic Literacy?

$\square$ Always $\square$ Most of the time $\square$ About half the time $\square$ Sometimes $\square$ Never

16. How often did you repeat out loud while viewing videos from Coptic Literacy?

$\square$ Always $\square$ Most of the time $\square$ About half the time $\square$ Sometimes $\square$ Never

17. What did Coptic Literacy help you with? Select all that apply.

$\square$ Letter names $\square$ Letter sounds $\square$ Letter combination sounds $\square$ Finding Coptic language resources

18. Are you interested in continuing to learn Coptic?

$\square$ Yes $\square$ Maybe $\square$ No

19. What are you interested in learning? Select all that apply.

$\square$ Grammar $\square$ Vocabulary $\square$ Writing

20. Provide any additional information about your experience using Coptic Literacy.

\section{References}

Botros, Ghada. 2006. Religious identity as an historical narrative: Coptic Orthodox immigrant churches and the representation of history. Journal of Historical Sociology 19: 174-201. [CrossRef] 
Brenzinger, Matthias, Arienne M. Dwyer, Tjeerd de Graaf, Colette Grinevald, Michael Krauss, Osahito Miyaoka, Nicholas Ostler, Osamu Sakiyama, María E. Villalón, Akira Y. Yamamoto, and et al. 2003. Language vitality and endangerment. Paper presented at International Expert Meeting on UNESCO Programme Safeguarding of Endangered Languages, Paris, France, March 10-12.

Cru, Josep. 2015. Language revitalisation from the ground up: promoting Yucatec Maya on Facebook. Journal of Multilingual and Multicultural Development 36: 284-96. [CrossRef]

Crystal, David. 2014. Language Death. Cambridge: Cambridge University Press, ISBN 9781139923477. First published 2000.

Cunliffe, Daniel. 2007. Minority languages and the Internet: new threats, new opportunities. In Minority Language Media: Concepts, Critiques and Case Studies. Edited by Mike Cormack and Niamh Hourigan. Clevedon: Multilingual Matters, ISBN 9781853599651.

Duolingo. n.d. Language Courses for English Speakers. Available online: https://www.duolingo.com/courses (accessed on 5 March 2019).

Eberhard, David M., Gary F. Simons, and Charles D. Fennig, eds. 2019. Ethnologue: Languages of the World, 22nd ed. Dallas: SIL International, Available online: http://www.ethnologue.com/ (accessed on 3 March 2019).

Foulin, Jean Noel. 2005. Why is letter-name knowledge such a good predictor of learning to read? Reading and Writing 18: 129-55. [CrossRef]

Gough, Philip B., and William H. Tunmer. 1986. Decoding, reading, and reading disability. Remedial and Special Education 7: 6-10. [CrossRef]

Groves, Robert M., Floyd J. Fowler Jr., Mick P. Couper, James M. Lepkowski, Eleanor Singer, and Roger Tourangeau. 2009. Survey Methodology. Hoboken: John Wiley \& Sons, Inc., ISBN 9780470465462.

Hermes, Mary, and Keiki Kawai'ae'a. 2014. Revitalizing indigenous languages through indigenous immersion education. Journal of Immersion and Content-Based Language Education 2: 303-22. [CrossRef]

Hermes, Mary, and Kendall A. King. 2013. Ojibwe language revitalization, multimedia technology, and family language learning. Language Learning \& Technology 17: 125-44.

Ishaq, Emile Maher. 1991. Coptic language, spoken. In Coptic Encyclopedia. Edited by Aziz Suryal Atiya. New York: Macmillan, vol. 2.

Jones, Ann. 2015. Social media for informal minority language learning: exploring Welsh learners' practices. Journal of Interactive Media in Education 2015: 1-9. [CrossRef]

Jones, Rhys James, Daniel Cunliffe, and Zoe R. Honeycutt. 2013. Twitter and the Welsh language. Journal of Multilingual and Multicultural Development 34: 653-71. [CrossRef]

Krauss, Michael. 2007. Classification and terminology for degrees of language endangerment. In Language Diversity Endangered. Edited by Matthias Brenzinger. Berlin: Mouton de Gruyter, pp. 1-8. ISBN 9783110197129.

Loprieno, Antonio, and Matthias Müller. 2012. Ancient Egyptian and Coptic. In The Afroasiatic Languages. Edited by Zygmunt Frajzyngier and Erin Shay. New York: Cambridge University Press, pp. 102-44. ISBN 9780521865333.

Moseley, Christopher. 2010. Atlas of the World's Languages in Danger, 3rd ed. Paris: UNESCO Publishing, Available online: http://www.unesco.org/culture/en/endangeredlanguages/atlas (accessed on 12 November 2018).

Ragheb, Nicholas. 2018. Coptic ethnoracial identity and liturgical language use. In Contemporary Christian Culture: Messages, Missions, and Dilemmas. Edited by Omotayo Banjo and Kesha Morant Williams. Lanham: Lexington Books, pp. 147-62.

Ramzy, Carolyn M. 2013. Music: Performing Coptic expressive culture. In The Coptic Christian Heritage: History, Faith, and Culture. Edited by Lois M. Farag. New York: Routledge, pp. 160-76. ISBN 9781134666843.

Saad, Saad Michael. 2010. The contemporary life of the Coptic Orthodox Church in the United States. Studies in World Christianity 16: 207-25. [CrossRef]

Saldaña, Johnny. 2016. The Coding Manual for Qualitative Researchers, 3rd ed. Los Angeles: Sage Publications, ISBN 9781473902480.

Simons, Gary F., and Charles D. Fennig, eds. 2018. Ethnologue: Languages of the World, 21st ed. Dallas: SIL International, Available online: http://www.ethnologue.com/ (accessed on 12 November 2018).

Smith, Aaron, and Monica Anderson. 2018. Social Media Use in 2018. Washington: Pew Research Center.

Spolsky, Bernard. 1995. Conditions for language revitalization: A comparison of the cases of Hebrew and Maori. Current Issues in Language and Society 2: 177-201. [CrossRef]

Stern, Alissa Joy. 2017. How Facebook can revitalise local languages: lessons from Bali. Journal of Multilingual and Multicultural Development 38: 788-96. [CrossRef] 
Takla, Hany N. 2014. The Coptic language: The link to Ancient Egyptian. In The Coptic Christian Heritage: History, Faith, and Culture. Edited by Lois M. Farag. New York: Routledge, pp. 179-94. ISBN 9781134666843.

Warner, Sam L. No'eau. 2001. The movement to revitalize Hawaiian language and culture. In The Green Book of Language Revitalization in Practice. Edited by Leanne Hinton and Ken Hale. Leiden: Brill, pp. 133-44. ISBN 978900425449.

Westbrook, Donald A., and Saad Michael Saad. 2017. Religious identity and borderless territoriality in the Coptic e-diaspora. Journal of International Migration and Integration 18: 341-51. [CrossRef]

Younan, Sameh. 2005. So, You Want to Learn Coptic? A Guide to Bohairic Grammar. Sydney: St. Mary, St. Bakhomious, and St. Shenouda Coptic Orthodox Church Kirawee.

(C) 2019 by the author. Licensee MDPI, Basel, Switzerland. This article is an open access article distributed under the terms and conditions of the Creative Commons Attribution (CC BY) license (http://creativecommons.org/licenses/by/4.0/). 